\title{
OTIMIZAÇÃO DA PRODUÇÃO DAS ENZIMAS LACASE E MANGANÊS PEROXIDASE POR PLEUROTUS SAJOR-CAJU EM RESÍDUO DE SYAGRUS CORONATA
}

\author{
$\underline{\text { Jéssica Santana dos Santos }}^{1}$ e Hélio Mitoshi Kamida ${ }^{2}$ \\ 1. Bolsista PROBIC/UEFS, Graduanda em Ciências Biológicas, Universidade Estadual de Feira de Santana, e-mail: \\ jeu_santiny@hotmail.com \\ 2. Orientador, Departamento de Ciências Biológicas, Universidade Estadual de Feira de Santana, e-mail: \\ hmkamida72@gmail.com
}

PALAVRAS-CHAVE: Pleurotus sajor-caju.; Syagrus coronata; Enzimas ligninolíticas

\section{INTRODUÇÃO}

Atualmente vem sendo muito utilizado resíduos agroindustriais como substratos em bioprocessos, uma excelente alternativa, tendo em vista o baixo custo desses substratos, além de resolver problemas ambientais gerados pelo descarte inapropriado desses resíduos.

O gênero Pleurotus é relato como sendo eficientes colonizadores e degradadores de lignoceluloses. Estes fungos realizam a degradação enzimática da porção lignocelulósica dos substratos pela elaboração das enzimas como lacases, manganês peroxidases e lignina peroxidases que estão envolvidas na degradação de ligninoceluloses (Qinnghe et al., 2004; Palmieri et al., 2000). Os mesmos formam um grupo altamente degradativo que atuam sobre constituintes maiores de resíduos ligninocelulósicos, como a celulose, a hemicelulose e a lignina (Shishido, 1992). Muitos destes microrganismos são capazes de fazer a bioconversão desses substratos lignocelulósicos em compostos de fácil assimilação para o seu metabolismo, onde as enzimas hidrolíticas tem papel fundamental nessa bioconversão, e agem conjunta e sinergisticamente na formação de um complexo com várias enzimas (Valasková e Baldrian, 2006). Atualmente, estas enzimas são utilizadas em várias aplicações industriais e a demanda por enzimas mais estáveis, altamente ativas e específicas tem crescido rapidamente.

Neste contexto, a importância dessa pesquisa se dá pela vantagem ambiental da conversão de resíduos agroindustriais e na produção enzimática por fungos. A utilização de resíduos agroindustriais representa uma alternativa para as indústrias de biotecnologia obterem enzimas hidrolíticas e oxidativas com um custo mais baixo em relação às enzimas que estão no mercado.

\section{MATERIAL E MÉTODOS}

\section{Aquisição, Preservação e Manutenção da Linhagem}

A linhagem de Pleurotus sajor-caju foi obtida por doação da EMBRAPA/CENARGEN-DF, sendo preservada conforme metodologia de Castellani (1967) na CCMB-UEFS. Em seguida, mantida em meio BDA, incubada em BOD à $28 \pm 1^{\circ} \mathrm{C}$ na ausência de luz, sendo repicada mensalmente.

\section{Coleta, Processamento e Armazenamento do Resíduo}

O resíduo da palmeira $S$. coronata (bráctea) foi coletado no município de Feira de SantanaBA. Este, seco a temperatura ambiente, foi triturado em trituradora de forragem e em moinho de facas, sendo armazenados ao abrigo da luz e umidade.

\section{Avaliação do crescimento micelial}


O resíduo foi misturado de acordo com o planejamento experimental definido por meio do software Statistica, tendo como variáveis a temperatura e o $\mathrm{pH}$. Para a avaliação do crescimento micelial, foram traçadas duas retas perpendiculares, medidas a cada $24 \mathrm{~h}$ durante 5 dias. As análises foram feitas em triplicata.

\section{Determinação da atividade enzimática das enzimas}

A atividade das enzimas lacase e manganês peroxidase foram determinadas por leituras espectrofotométricas, em intervalo de 7 dias durante um período de 28 dias de incubação. A atividade da lacase foi determinada a $420 \mathrm{~nm}$, empregando ABTS: 2,2'-azino-bis (3ethylbenzothiazoline-6-sulfonic acid) como substrato enzimático (Han et al.,2005) e a de manganês peroxidase, a $610 \mathrm{~nm}$, pela oxidação do vermelho de fenol (Kuwahara et al., 1984).

\section{RESULTADOS E DISCUSSÃO}

\section{ENSAIO EM PLACA DE PETRI}

$\mathrm{Na}$ tabela abaixo, observa-se o resultado do crescimento do fungo Pleurotus sajor-caju em diferentes combinações das variáveis estudadas, no resíduo da bráctea de Syagrus coronata, durante 5 dias de cultivo.

Tabela 1- Valores médios de crescimento micelial de Pleurotus sajor-caju em resíduo de Syagrus coronata após 5 dias de cultivo.

\begin{tabular}{llll}
\hline ENSAIO & TEMPERATURA ${ }^{\circ} \mathrm{C}$ & $\mathrm{pH}$ & $\begin{array}{l}\text { CRESCIMENTO } \\
\text { MICELIAL }(\mathrm{cm})\end{array}$ \\
1 & 19,4 & 3,9 & 3,1 \\
2 & 40,6 & 3,9 & 0,5 \\
3 & 19,4 & 13,1 & 3,0 \\
4 & 40,6 & 13,1 & 0,5 \\
5 & 15 & 8,5 & 2,2 \\
6 & 45 & 8,5 & 0,5 \\
7 & 30 & 2 & 0,5 \\
8 & 30 & 15 & 3,1 \\
9 & 30 & 8,5 & 3,3 \\
10 & 30 & 8,5 & 3,2 \\
11 & 30 & 8,5 & 3,1 \\
\hline
\end{tabular}

Através dos resultados obtidos verificou-se que o $\mathrm{F}$ calculado foi 5,85 e a porcentagem de variação 60\% (tabela 2) indicam uma boa concordância entre os valores experimentais e o previsto no modelo (tabela 1 e figura 1 ).

Tabela 2- Análise de variância para o substrato bráctea de Syagrus coronata

\begin{tabular}{lllll}
\hline Fonte de Variação & S.Q & G. L & Q.M & F calculado \\
Regressão & 9,93 & 2 & 4,97 & 5,85 \\
Resíduos & 6,78 & 8 & 0,85 & \\
Total & 16,71 & 10 & & \\
\hline
\end{tabular}




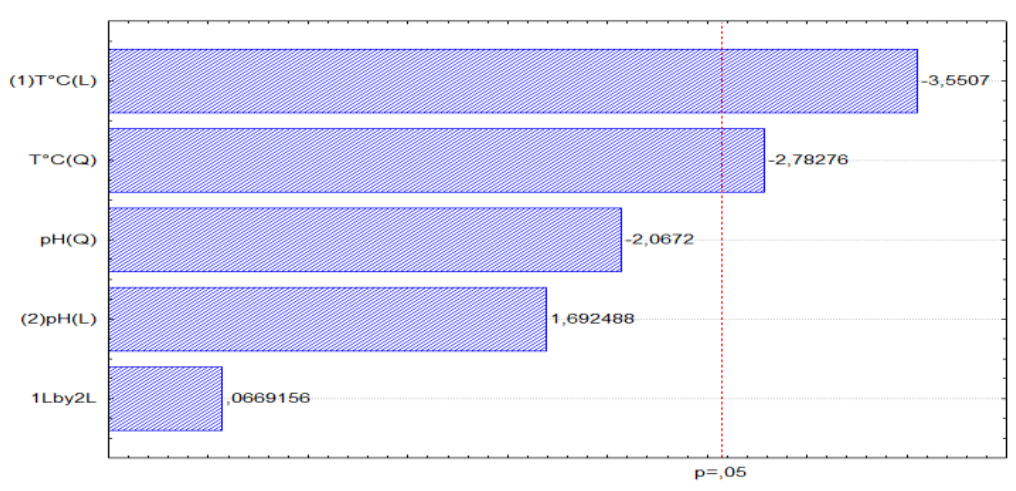

Figura 1- Diagrama de Pareto para a otimização das condições de cultivo no resíduo de Syagrus coronata

A análise estatística apresentada na figura 2 demonstra que o $\mathrm{pH}$, não interferiu significativamente no crescimento do fungo em placa. Porém a temperatura na faixa de $20{ }^{\circ} \mathrm{C}$ a $35^{\circ} \mathrm{C}$, apresentou-se como a região ótima de crescimento.

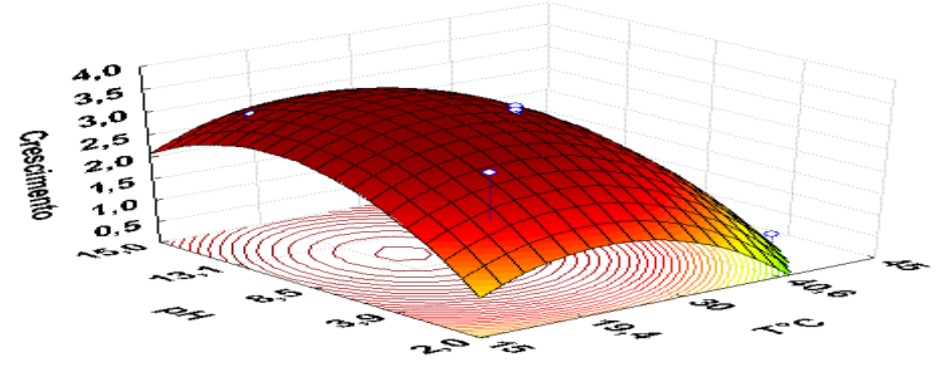

Figura 2- Curva de contorno em função das variáveis independentes do fungo Pleurotus sajor-caju em função do $\mathrm{pH}$ e temperatura.

\section{FERMENTAÇÃO SEMISSÓLIDA E ANÁLISE DA ATIVIDADE DAS ENZIMAS}

As condições escolhidas para avaliar a produção das enzimas na fermentação semissólida consistiam em uma temperatura a $30^{\circ} \mathrm{C}$ e $\mathrm{pH} 8,5$, condições essas significativas segundo o planejamento experimental feito em placa e a análise estatística.

\section{ATIVIDADE DA ENZIMA LACASE}

Os resultados apresentados no gráfico da figura 3 demonstram que houve atividade enzimática da lacase em todos os dias de incubação analisados. Apresentando picos de atividade enzimática no $28^{\circ}$ dia de cultivo de $666,5 \mathrm{U} / \mathrm{L}$.

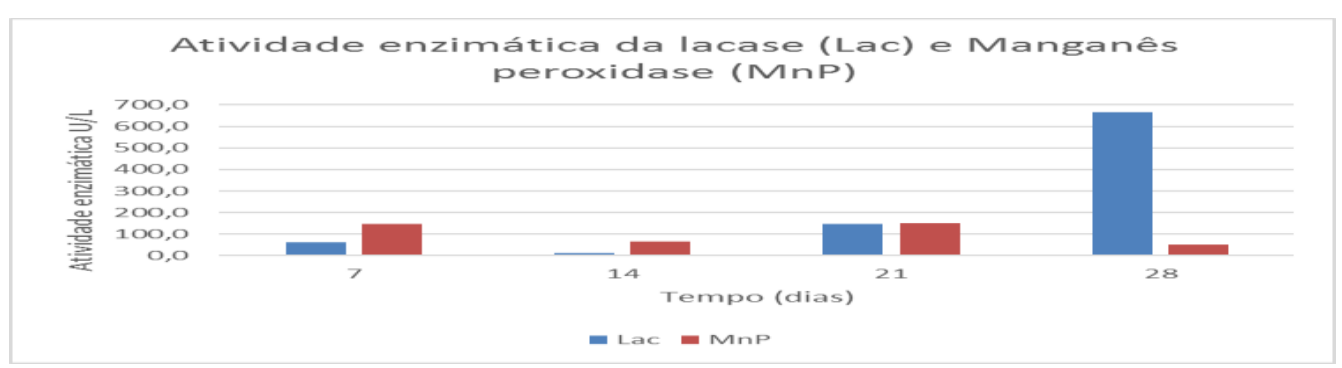

Figura 3- Atividade das enzimas lacase e manganês peroxidase em resíduo de bráctea por Pleurotus sajor-caju 
Segundo Alves (2010) o metabolismo primário, na ausência de indutores, produz pequenas concentrações de lacase sendo que a produção de enzimas ligninoliticas está associada com o metabolismo secundário. Sendo assim, a atividade enzimática da lacase em altas concentrações tem relação com o metabolismo secundário do fungo, que não é dependente do seu crescimento, mas sim de algum fator externo.

\section{ATIVIDADE DA ENZIMA MANGANÊS PEROXIDASE}

Os resultados apresentados no gráfico da Figura 3 atestam que em todos os períodos de incubação foram detectadas atividades enzimáticas de manganês peroxidase. Sendo que as atividades oscilaram entre $151,12 \mathrm{U} / \mathrm{L}\left(21^{\circ} \mathrm{dia}\right)$ e $51,12 \mathrm{U} / \mathrm{L}\left(28^{\circ} \mathrm{dia}\right)$. A atividade da MnP é produzida durante o metabolismo secundário e é regulada pelas concentrações de carbono e nitrogênio no meio de cultura. É catalicamente dependente de $\mathrm{H}_{2} \mathrm{O}_{2}$ e íons $\mathrm{Mn}$ (II), e acetoácidos que estabilizam a sua atividade oxidativa (Valasková, 2006).

\section{CONSIDERAÇÕES FINAIS}

Diversos estudos vêm buscando estratégias sustentáveis para a utilização dos resíduos ligninocelulósicos gerados pelas atividades agroindustriais, tendo em vista que boa parte destes materiais são descartados no ambiente o que pode vim a causar possíveis danos. Os resultados obtidos neste trabalho sustentam o uso de resíduos lignicelúlosicos do licuri (bráctea) como um substrato adequado para a produção das enzimas lacase e manganês peroxidase, ambas com grande potencial de uso em diferentes processos industriais, além do fungo Pleurotus sajor-caju ser um potencial produtor dessas enzimas.

\section{REFERENCIAS}

ALVES, F. Modelagem e simulação de biorreator operando com fungos Trametes Versicolor para produção de enzima lacase. Dissertação de Mestrado. Instituto Mauá de Tecnologia, São Caetano do Sul, SP, 80p, 2010.

CASTELLANI, A. Maintenance and cultivation of the common pathogenic fungi of man in sterile distilled water. Further researches. Instituto de Medicina Tropical, Lisbon, 181-184, August, 1967.

PALMIERI, G.; GIARDINA, P.; BIANCO, C.; FONTANELLA, B.; SANNIA, G. 2000. Induction of laccase isoenzymes in the ligninolytic Fungus Pleurotus ostreatus Appl and Environmental Microbiology. 1:920-924.

QINNGHE, C.; XIAOYU, Y.; TIANGUI, N.; CHENG, J.; QIUGANG, M. 2004. The screening of culture condition and properties of xylanase by white-rot funfus Pleurotus ostreatus. Process Biochemistry,39:561- 1566.

SHISHIDO, K. 1992. The application of molecular genetics to oriental mushrooms. Applied molecular genetics of filamentous fungi, 9:201-213.

VALASKOVÁ, V.; BALDRIAN, P. 2006. Estimation of bound and free fractions of lignocellulosedegrading enzymes of wood-rotting fungi Pleurotus ostreatus, Trametes versicolor and Pictoporus betulinus. Research in Microbiology, 157(2):119-124. 